\title{
Integration of Building Interior and Outdoor Design
}

\author{
Haobin Fu \\ College of Art and Design, Nanyang Institute of Technology, \\ Nanyang, 473000, China
}

\begin{abstract}
With development and progress in social economy, the development of China's building industry is greatly driven. Moreover, with continuous improvement of people's living level, people propose a higher requirement for building design. Through overview on whole building, it can be found that the functions of building can be shown only via effective combination of building interior and outdoor design to bring people integrated feeling. In order to continuously meet people’s housing demand and promote China's building industry to develop toward an ideal direction, this paper gives a detailed explanation on the integration of building interior and outdoor design so as to provide certain reference for relevant department and working staff.
\end{abstract}

Key words: building; interior and outdoor design; integration

The so-called integration of interior and outdoor design refers to giving a full consideration on integration of building interior and outdoor space in the process of designing the building to adapt to overall development demand of one city so that the functions of building can be truly exerted and the interior and outdoor space of building can be gradually developed toward society and human-oriented direction. Therefore, the relevant units and construction personnel shall pay attention to this aspect so as to promote effective development of China's building industry.

\section{Analysis on building form and function}

1. Under new historical background, the society endows deeper definition with the building design which shall be a kind of use of new function and form so as to satisfy people’s aesthetic demand in new period. Therefore, we shall continuously perfect the 
interior and outdoor space design system to ensure that people can live in a more beautiful environment. In this way, we shall analyze the architecture system to continuously optimize building interior and outdoor design scheme, ensure the perfectness of various kinds of theoretical systems, and apply more building forms for the purpose of improving functional value significance and aesthetic significance of buildings and ensuring that various kinds of new building forms can be effectively constructed, thus the interior and outdoor design problem existing at current stage can be solved.

Through analysis on buildings, it is able to obtain the function of works of art; through application of exquisite building design, it is able to improve the standard of building interior and outdoor design and ensure to effectively show interior and outdoor modeling of building so as to effectively combine structural design module and function module; therefore, we shall abandon some old design concepts, and continuously update design concepts, and then satisfy current design and demand of building structure to ensure perfect structure system, and then further continuously innovate building structural style and building design to ensure uniform building function and building form.

2. In order to satisfy current demand of building design, it is very necessary to analyze people's functional demand; the certain difference existing in people's daily life causes certain influence on building form, and people are influenced by building form in daily life to certain degree. Through analysis on building function and building form and division of different building style, we can get a more clear knowledge of application style of building and then distinguish different types. Firstly, it is required to realize an organic combination of perfect use function, advanced structural system, beautiful building modeling, and applicable and economic buildings; secondly, it is required to pursue for some novel artistic effect, create unique artistic modeling, include the structure scheme in incompletely reasonable building design, and give up the economic and reasonable structural design; in terms of building interior and outdoor design, we shall realize effective integration of interior and outdoor design to perfectly show building functions. 


\section{Integration of building interior and outdoor design}

The building environment and the use property of building space determine the integrated design of building interior and outdoor space; we shall use artistic handling means and material technology means to master the space as a whole and design the shape and size to keep internal and external harmony.

In order to make people feel satisfied with their comfortable movement and life, a comprehensive consideration shall be given to arrangement of facilities and internal and external environmental demand. Therefore, the main purpose of building interior and outdoor space design is to satisfy people's material and spiritual demand of interior and outdoor building.

\section{Analysis on key points of integration of building interior and outdoor design}

In the process of building interior and outdoor design, we shall satisfy people's psychological and physiological demand, make an integrated treatment on interpersonal communication and the relationship between people and nature, and satisfy people's multiple demands such as economic benefit, comfortable and beautiful performance, environmental atmosphere, and using functions on the basis of serving the people. The design and implementation are greatly related with the factors such as equipments, materials, construction management, and quota rules. Therefore, it can be said that a systematic engineering with strong integrity is the main feature of current interior design, and serving the people and interpersonal relationship are the starting point and end result of modern interior and outdoor design. The integrated interior and outdoor environmental design is the so-called modern interior and outdoor design which covers engineering technology and visual environment, and also covers artistic environment (light, heat, and sound, etc.), atmosphere, physical environment, and other cultural connotation and psychological environment.

\section{Effective integration of interior and outdoor light}

In the interior space of building, people's visual functional demand can be met via use of light, and there exists certain aesthetic factor, and the light is also important indoor heating. Meanwhile, the light can create the space, bring certain damage and change on spatial environment, and also cause serious influence on texture, color perception, 
and size. Therefore, in the process of indoor lighting design, in order to show integrated features, it is required to give a comprehensive consideration on climate, landscape, illuminance, and indoor and outdoor environment. Besides, we shall not only consider direct light, but also consider emitted light and diffused light.

\section{Interior and outdoor space decoration}

With continuous development of urban buildings, the area of greenbelt is reduced to a certain degree. People always live indoor due to long-term life and work, thus each greenbelt shall be fully applied and some green plants can be transplanted indoor so as to improve indoor spatial and environmental quality and provide certain guarantee for people’s physical and mental development. Besides, in indoor space, the green plants are very important decoration; it can effectively motivate people's spirit and can be used to design indoor environment via outdoor means.

As for indoor space of buildings, we can utilize "afforesting”. In general, we can place some green plants on both sides of screen, at enhance of hall, or near floor cabinet or sofa so that the green plants can have obvious function in separating space and being used as route mark, break the monotony of indoor space, and fully apply the softening function into rigid space. Through transplanting outdoor green flowers and plants into indoor space, it is not only able to effectively purify the air, but also able to effectively add natural vitality into boring indoor space and provide people with fresh visual beauty. The spatial level can be enriched by use of afforesting; the combination of furnishings and furniture can create integrated three-dimensional decoration structure and form main-body pattern and background pattern via comparison and union.

3. Integration of interior and outdoor landscape

In China's cultural history, China's traditional landscape art is a bright pearl. Nowadays, we still apply many traditional landscaping means, such as Suzhou Humble Administrator's Garden and Beijing Summer Place, both of which are very famous classical gardens; furthermore, after the new China is founded, some gardens of new time are also constructed. In terms of interior design, we apply landscaping techniques and enhance the communication between interior space and outdoor space to integrate outdoor environment into indoor space. The landscaping method 
"enframed scenery" is the most typical method in which we use indoor doors and windows as simulated scenery frame to blend into outdoor scenery; in this way, within certain indoor space, people can appreciate beautiful scenery. The fountain, waterfall, brook, algae, and unique mountains and plants are main outdoor decoration or natural landscape; in the fatigued and tense cities, we make great efforts to introduce outdoor landscape and design way into interior design. In this way, people can effectively feel the existence of nature in indoor life, seek for maximum harmony and integration, and mitigate the physical and psychological pressure brought by urban fierce competition. In the central nave and hall of some public places such as restaurants and hotels, we can often see such design. The diaphanous glass cover structure is the main material used in ceiling in those places, thus it is able to provide sufficient light condition for some ornamental animals and plants. The bright and spacious in-hall space provides the designers with rich imaginary space. It is able to arrange green tress, fountain, or rocks among artificial hills, or arrange flowing water, bridge, pavilion, and waterfall to provide people with a feeling of being personally on the scene so that people can truly feel the charm of nature.

There are many examples about blending outdoor landscape art into interior design. Take Hyangsan Hotel as an example: on the basis of nature, this hotel creates a realm higher than nature and effectively integrates natural beauty and artificial beauty. In terms of whole structure, this hotel effectively applies the design techniques of gardens of southern Changjiang delta and also effectively applies the natural scenery; it is constructed near mountains and follows no set form; the several complex from floor 2 to floor 4 are separated via dozens of gardens and arranged in a scattered and natural way. Besides, the buildings are connected via winding corridor, and the common outdoor decoration such as pool water, trees, flowers and plants, winding paths, and rocks are integrated into interior design so as to further combine overall environment and show unique style of gardens of southern Changjiang delta.

\section{Effective integration of wall, doors and windows, and column}

In the interior space, the wall, as the main interface, is single with large area; after the outdoor elements are integrated, the wall is the position which can most show effect; 
in the process of controlling interior style, some excellent design personnel are very good at handling the wall and pay great attention to this aspect. In some indoor environment, in case of large space, there will be large beam columns with large volume, thus we absolutely can't ignore the decoration on columns. The “outdoor orientation” wall column decoration mainly refers to directly or indirectly apply outdoor natural building, boulder strip, marble, and cobble as main materials; except for natural geological materials, the materials such as ventilating duct and industrialized mechanical structures are also applied into post-modern interior design. Through exposing those materials in indoor space, it is able to realize the "indoor orientation” decoration purpose. In the interior decoration for entertainment venues full of bright uniqueness and smell of time such as coffee house or dance hall, the industrial structure or natural materials are effectively applied by design personnel on the wall to show plain primitive beauty or create rough natural beauty or express the nostalgia to hometown.

The outdoor orientation windows and doors can be divided into two types: firstly, in the process of selecting door frame or door materials, the natural log is used; secondly, the wall opening is applied to naturally create outdoor door opening, and this method is often applied in semi-closed grate door; in consideration of protection function, this method can't be directly applied on directly outward windows and doors. In indoor natural lighting, the windows are main means; the reasonable decoration and skillful design can realize the purpose of active atmosphere and exert the function of outdoor natural fun. In general, at up and down or both sides of windows, the fixed window fan decoration is installed, and the practical function of this decoration has been eliminated; this is not the outdoor window of traditional significance, but glass house constructed via taking the metal such as lightgage steel joist as framework; through use of large-scale screen glass, it is able to construct a transparent house, thus this decoration can greatly expand indoor space to certain degree and it is the most effective extension as for introduction of outdoor space into indoor space. As for resisting against wind and rain, this space also exerts important function; besides, people can enjoy outdoor scenery. Due to transparency, the outdoor people can also 
appreciate all indoor scenery, thus it is able to realize effective integration of interior and outdoor design.

\section{Conclusion}

In a word, with continuous development of building industry, people propose new requirement for design of building structure, and there is stronger and stronger trend for integration of interior and outdoor design; the humanity of building design can be highlighted only via their effective integration. Therefore, the integration of interior and outdoor design is a very important development direction for design of building structure at current stage.

\section{References}

[1] Shi Lizhi: Analysis on Design Scheme for Building Interior and Outdoor Space [J], Engineering Technology \& Management, 2011 (09).

[2] Xie Cuiqin, Ding Mijin, Fan Cunxing: Representation of Minimalist Art in Building Interior and Outdoor Environmental Design [J], Inner Mongolia Science \& Technology and Economy, 2007 (08).

[3] Zhong Lei, Zheng Guiyu: Color Expression and Spatial Color Design - Relation between Color and Space in Building Interior and Outdoor Design [J], Art Panorama, 2011 (09).

[4] Huang Changqin: Integrated Design of Building Interior and Outdoor Environment [J], Architectural Design Analysis, 2011 (09).

[5] Xu Bo, Quan Huimin: Discussion on Trend of Integration of Interior Design and Outdoor Space [J], Architectural Analysis, 2011 (09). 